\title{
Prospects for Afghan Women After Repatriation
}

\author{
by Nancy Hatch Dupree
}

\section{Introduction and Background}

Since the April 1988 signing of the Geneva Accords calling for the withdrawal of Soviet troops from Afghanistan, there has been a flurry of planning for repatriation and reconstruction. Hastily convened teams of "Afghan experts" vie with one another for the anticipated cascades of monies these plans will generate. Few adequately address the special needs of women.

This stems in part from the fact that planners feel intimidated by the heavier than normal restrictions Afghans have imposed on women among the refugee populations in Pakistan, a predictable reaction taken by most beleaguered cultures. In Afghanistan, women traditionally symbolized the honour of family, tribe, and nation; they were also esteemed as perpetuators of Afghan cultural values. Following the installation of a leftist government in 1978 and the subsequent occupation by foreign troops in December 1979 , women came to symbolize the honour of the jihad (struggle) as well.

While it is true that the jihad is being fought in the name of Islam, it is also most importantly regarded as a struggle to maintain national ideals, including the safekeeping of those values entrusted to women. The foreign invaders have been expelled, but resistance efforts continue to depreciate the Kabul regime through the medium of Islam, summarily rejecting all the reforms advocated by the enemy as being un-Islamic. This resurgence of social conservatism is most clearly demonstrated by the tightening of practices relating to participatory roles for women in the public sector.

Greater insistence on the application of purdah (seclusion) and wearing of the veil have placed a heavy burden on both rural and urban women. Rural women enjoyed considerable freedom of movement within their kin-oriented villages where the support of their women's networks, together with the mutual respect generated by closely interrelated economic roles with men, fostered self-esteem. Among the refugee populations, these networks have largely broken down, male/female roles have been set apart, and dense overcrowding of peoples of diverse origins has confined women to their homes.

Rural women, therefore, feel frustrated and marginalized; some even express a diminishing sense of self. It would be a grave disservice, however, to suggest that these women feel defeated. Their courage is inspirational. They accept their responsibilities in maintaining the solidity of the family which in Islam represents the basic foundation of the society's well-being. The remarkably few incidents of delinquency or drug abuse among refugee youth attest to the success of women's efforts.

On the whole, these rural women anticipate repatriation with admirable composure. It may be that, after all they have experienced, the future cannot be imagined as any worse than what they have already endured. It may also be that many cannot conceive of what a monumental task lies before them. Regardless, they fret over the delay in returning and fully intend to be part of the rebuilding process. Also, despite restrictions on movement, rural and small-town women have been exposed to many new services, including health, sanitation, potable water schemes, and education for children, which have heightened and broadened their expectations. They will call for these on their return. Their voices should be heard.

There are two segments of urban women to be considered. Middle-class women did not have a tradition of working outside the home. In fact, extradomestic pursuits for women were thought to bring shame on both the women engaging in them and their male family providers. Many refugee women from these groups, however, have taken advantage of employment opportunities either because of economic necessity or in response to the belief that helping the less fortunate, especially widows and orphans, contributes to the overall efforts of the jihad. Working women, therefore, have gained respect in the refugee situation through involvement in valued activities.

These women from mainly educated, mid-income, urban families are candidly pragmatic when they speak of the future. Here their work is respected because it is an important part of the jihad. But many members of their families remain in Afghanistan and have no concept of the refugee mentality. Will these members be reconciled to the idea of women producing items for sale or attending workplaces outside the home? Or will they still consider it shameful for women to extend the traditional boundaries of the women's domain? Social pressures will figure prominently in determining what these women may or may not do on their return.

Women also worry about the attitudes of younger men, whose lives have been totally consumed by emotions rising from ten years of war. When the enemy has gone, these women ask, who will be the object of their aggressions? May it not take the form of restricting, or even suppressing, women?

While acknowledging that difficulties will arise, most women concede that their former, purely domestic life-styles will probably seem too confining when they return. They must be offered opportunities which are culturally acceptable.

The second segment within the urban milieu consists of women from progressive technocrat, professional, and élite families who, before 1978, took higher education and public careers for women for granted. These women have been most severely curtailed by the pervasive- 


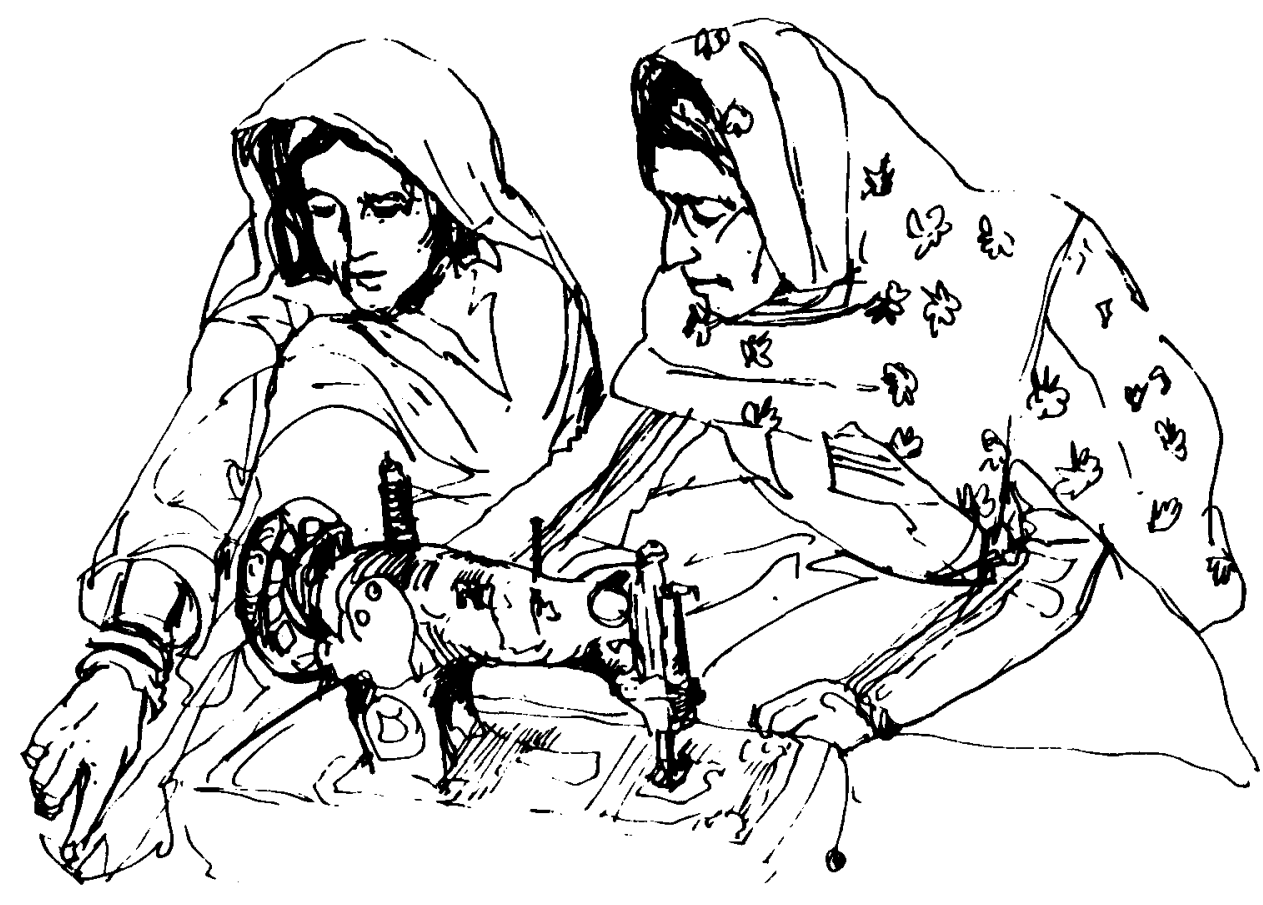

ness of neoconservative attitudes which constrain refugee women through innuendo and outright threats. This has persuaded many professional families to leave for Western countries. The talents of these professional women will be sorely missed, and expanded training of replacements will consequently be of high priority.

During the decade since 1978 there has been some slight modification in attitudes toward women's roles. Initially, even primary education for girls was anathema. Enrollment gradually increased over the years, but the majority continue to drop out on reaching puberty, for education is regarded as central to change - a tool of infidels - and most traditionalists are hostile to any changes in male/female relationships which they assert will result if women are educated. In the past, even some intellectuals who promoted the principle of women's rights as a tenet of Islam would not tolerate liberated women in their own households.

Still, within the last three to four years a veritable explosion in educational and career activities has taken place among young women from educated professional and mid-range bureaucratic families. Although the numbers are small considering the total refugee population and participants by no means enjoy anything remotely akin to educational and

\section{Current Imperatives}

To meet these needs Afghan women must not be left invisible. Processes allowing their voices to be heard need to be institutionalized.

This does not mean isolating women's programmes and relegating them to separate bureaucratic agencies. Focusing special attention on purely women's issues would be disastrous in the present volatile situation, for this would certainly attract determined, even violent, opposition from neotraditionalists.

Rather, each reconstruction programme should have its integrated women's component within each sector/phase of repatriation, development, and implementation, so as to maximize women's input - from active planning roles through career enhancement.

Over a million war casualties, a high proportion young males in the prime of life, have robbed the workforce and altered the demography. Women, many single unmarrieds and widows, will predominate and should be prepared to contribute substantially to the national economy. Therefore, in addition to the traditionally acceptable fields of health, education, and child care, skills will be needed in administration, management, business administration, communications, radio programming, computer sciences, construction, engineering, industry, commerce, and agriculture. It is reported that English-language programmes are making a big comeback in Kabul today; they have been enormously popular in Pakistan for some time.

For rural women, programmes should focus on reestablishing the close interrelationships women and men formerly enjoyed through the promotion of such agriculturally-oriented projects as milch cows, sheep, goats, and poultry; fruit and vegetable cultivation and processing; sericulture; etc. A wide variety of cottage industries and handicrafts might also be developed to generate income beyond purely domestic spheres.

It will not be enough, however, merely to provide women with animals and supplies. They too should be included in extension training schemes, particularly in veterinary practices, to reduce the incidence of diseases that currently threatens to take an even greater toll than was customary in the past. Small credit schemes may be necessary. This horrifies unimaginative planners who forget, perhaps, that 
time and again women of the Third World have proved to be better credit risks, less likely to default, than men. Implementing such projects will not be easy, but the situation calls for innovative thinking and courage.

For urban women, it must be realized that, initially, separate-but-equal policies may well prevail. Typically, such separate institutions are far from equal, but this does not need to be so if equitable planning, financing, equipping, and monitoring are assiduously promoted. "Separate" need not imply "inferior" - if vigilance is institutionalized. Indeed, given the opportunity, it can be predicted with reasoned optimism that women will excel scholastically over their male peers.

While preparing women for development-oriented roles one should not neglect to note that, for both rural and urban women, motherhood will remain a primary option. Programming should as a result target the physical and social needs of children and mother-child development. This will require training and programming in all aspects of health, but physiotherapy training for women from all social strata is particularly crucial. Women carry most of the burden of caring for the war-related handicapped men, women, and children who number in the unknown tens of thousands.

This further raises the need for community services, much neglected in the past, to make up for the lack of a centralized health infrastructure which will be a long time in materializing.

This discussion serves only to highlight the infinite variety of opportunities which could be opened to women. Whatever the programme, however, designs would best be family/community-oriented, based on traditional women's network models, and implemented locally, avoiding overcentralization. Such approaches offer the greatest, if not the only, chance of successfully providing women a respected place in society while strengthening community cohesiveness. The positive promotion of individual selfesteem in this manner will have a considerable impact on the society as a whole. In order to realize these goals it should be reemphasized that Afghan women must be afforded a fully participatory role in planning. There are many talented women living in Pakistan, but they have no forum. Who are they? Where are they? It is time to seek them out and provide them with an arena in which to articulate goals and exchange ideas.

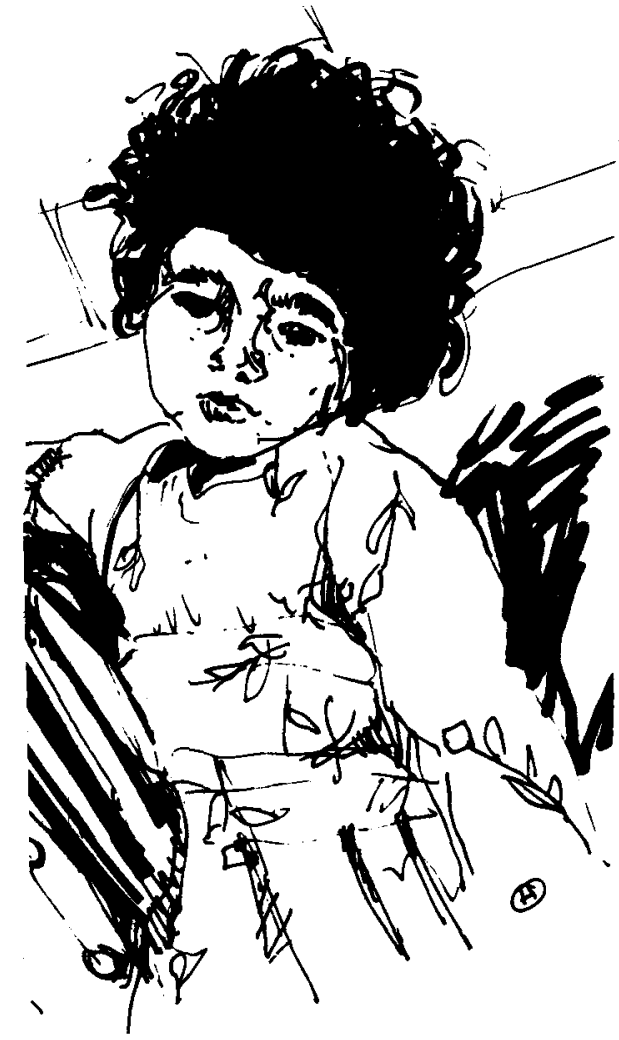

Involving women in planning is of utmost urgency at this particular moment because many Afghans, moderate and conservative, are sincerely apprehensive about what they call "cultural imperialism": now that the foreign military invaders have been repulsed, other outsiders, no matter how well-meaning they may be, sit poised, ready to engulf the nation with new sets of foreign values. At a seminar on Afghanistan held in Tehran (January 1989) numbers of speakers insisted that all Westerners be totally excluded from Afghanistan when a new Islamic government is installed.

Recent events in other parts of the Muslim world provide ample examples of similar reactions to perceptions claiming Westerners denigrate traditional Islamic values while seeking to impose their own. The best way to allay these fears is to make sure the Afghans formulate their own programmes. Humanitarian agencies can then facilitate implementation.

This approach is all the more important in designing programmes for women, who personify the essence of Afghan culture. Because of divergent outlooks within different segments of Afghan society, planning may have to be organized in a variety of small groups utilizing women's networks associated with various social and political alignments, despite the fact that proponents of centralized planning may view this tactic as hopelessly inefficient.

Working with smaller groups initially will also serve to contend with a natural passivity which tends to characterize educated and trained women, even during normal times. Afghan women have never been militant activists; public activists among women in Pakistan can be counted on the fingers of half $a$ hand. Nevertheless, Afghan women are a strong decision-making force in the family, and Afghan society emphasizes the collective identity of the family. Absence of an overt status does not therefore mean that women lack ideas, talent, or influence within their own spheres. By encouraging women to project themselves more fully, development in general can better be promoted while simultaneously preserving the traditional nature of Afghan society.

Nancy Hatch Dupree has undertaken research in Afghanistan - and among Afghan refugees in Pakistan - since 1962. Together with Louis Dupree she was involved with Islamic and Arabian Development Studies at Duke University.

\section{Reports on Afghan Refugees}

The Citizens Commission on Afghan Refugees has issued the following reports: "The Challenge of the Coming Afghan Refugee Repatriation: Fulfilling Our Commitments in the Final Chapter of the Afghanistan War: A Report on a FactFinding Visit of the Citizens Commission on Afghan Refugees - May 28-June 8, 1988", "The Challenge of the Coming Afghan Refugee Repatriation: Fulfilling Our Commitments in the Final Chapter of the Afghanistan War: Second Report on Afghan Refugees - Visit of October 10-19, 1988 ", and James C. Strickler, "Report of Visit $(5 / 22-5 / 28 / 89)$ to Peshawar and Hangu Pakistan". Copies available from the International Rescue Committee, Inc., 386 Park Avenue South, New York, NY 10016, USA; tel.: (212) 679-0010, fax: 212 689-3459. 